\title{
SOFTWARE DEFINED NETWORKS - A STEP TOWARDS A NEW GENERATION OF NETWORK SERVICES
}

\author{
Ivan Ivanov ${ }^{1}$, Georgi Hristov², Vanya Stoykova ${ }^{1}$ \\ ${ }^{1}$ Faculty of Technics and Technologies, Trakia University \\ 38 Graf Ignatiev str., 8600 Yambol, Bulgaria \\ e-mail: ivan.ivanov@uni-sz.bg, vanya.stoykova@trakia-uni.bg \\ "University of Ruse "Angel Kanchev" \\ 8 Studentska str., 7017 Ruse, Bulgaria \\ e-mail: ghristov@uni-ruse.bg
}

\begin{abstract}
Social networks, mobile apps, and cloud computing push traditional networks to the limits of their boundaries. One solution to this problem is Software Defined Networks (SDN), which is a contemporary networking concept that allows network administrators easy to manage network services and resources by differentiating the management plane from the data transport plane. The new generation of networks eliminate inefficiencies of the existent networks making them more automated, dynamic and easy adapting to the changing state and requirements of users.

The paper presents a comparative analysis of traditional and software defined networks on the base of their capabilities and application as the aim is the applying of SDN as a suitable solution of the problems of modern networks.
\end{abstract}

Keywords: Conventional network architecture, Software-Defined Networks, Network Routing.

\section{INTRODUCTION}

The growing interest of business, of all users of network services to different computing resources, necessitates the periodic updating of the information infrastructure. This upgrade process, along with the complexity it entails, further complicates the IT staff that has to manage more and more connected devices. The problems of scaling data networks pose a number of challenges for large business organizations, as modern user applications require more server resources, reliability, security and speed in obtaining resultant information. During peak loads, traffic between physical endpoints increases dramatically and may exceed the capacity of communication channels [8].

The more important trends that have generated a lot of discussion in recent years about a radical change in the construction of modern computer networks are the following:

- Increase in volume and redistribution of different types of network traffic. The software products used today are drastically different from those used in the dawn of the Internet, when the dominant method of accessing information resources was the classic version of the client-server model. Nowadays, in the context of virtualization of network resources and due to the integration of different business management systems (ERP, CRM, SCM, etc.), before returning the resultant information, applications need to access several servers with databases of different nature, often in various affiliates and offices of the company. This creates additional traffic between the respective servers and burdens the service environment significantly. On the other hand, company employees are increasingly demanding remote access to the corporate information environment from different computing devices. This, on the one hand, helps their remote work, but at the same time contributes to increasing network traffic. 


\section{ART'THE $Y^{2}$}

Ipplied Resseirlohes in Technics, Technologies and Bductation

Journal of the Faculty of Technics and Technologies, Trakia University https://sites.google.com/a/trakia-uni.bg/artte/

- Last but not least, many organizations are already relying on cloud services to improve their business profitability, resulting in increased WAN traffic and increased security, compliance and security requirements and audit [10].

- Increasingly dependent on Big Data. The processing of large data sets is accomplished through the parallel operation of multiple servers connected to each other. The rapid growth rate of these arrays creates the need for additional capacity and better management of the serving network infrastructure in the data centers [8].

- Another important trend is based on the BYOD (Bring Your Own Device) network infrastructure security policy and methods of protecting intellectual property while continuously accessing employees of modern corporations from their own devices (mobile phones, tablets, personal and mobile computers) to sensitive business information, programs, applications, and other IT resources.

- One of the trends that led to the emergence of SDN is the increasing level of virtualization and services and applications running on virtual machines. The static nature of traditional networks contrasts sharply with the dynamic nature of modern server-based environments, where resource virtualization is a prerequisite for the rapid growth of mobile users in need of network connectivity. The latter is one of the reasons that has led to a change in traffic patterns, as applications are distributed among multiple virtual machines that generate data flows among themselves [10].

Software Defined Network (SDN) is a new architecture that is dynamic, manageable, costeffective and adaptable, making it ideal for the dynamic nature of applications today. This architecture separates the functions of network management and routing (Routing), which allows network control to become directly programmable and the underlying infrastructure to be abstracted for applications and network services that can treat the network as a logical or virtual unit. In SDN, instead of managing separately network assets using separate interfaces, they are also collectively controlled by software through unified solutions running on the server cluster. The open source SDN platform offers a widely accepted API (Application Programming Interface) ecosystem that can be used to automate multilevel system configuration and optimization, including security and optimization devices used across levels. This means that the data themselves can often be managed more intelligently and efficiently at the network level - transmitted where necessary or blocked if they are considered a security threat [1].

This report provides a comparative analysis of traditional and Software Defined Networks, examines their capabilities, and their purpose is to present SDN as an appropriate solution to the problems of modern networks.

\section{SOFTWARE DEFINED NETWORKS}

A software defined network is a way of managing networks that separate the management plane from the forwarding plane. The evolution of SDN dates back to the 1980s, but it can be said that the immediate predecessor of SDN networks is the Ethane project [2, 16]. It was created in 2006 and defines a new network architecture for corporate networks. The project focuses on the use of a centralized controller for managing the behavior and security of networks. Similar to SDN, Ethane consists of two main components - a controller that decides how the data will be routed and an Ethane switch that performs the routing itself [10]. The approach of active networks, which emerged in the 1990s, is quite similar to what we see today with SDN, but still this technology is not needed at that time, since then hardware support is not cheap and the concept of centers is missing for data [4, 13]. The basic support technology for SDN comes in the form of network virtualization, which in its simplest form allows the software to operate separately from the underlying hardware. The idea of 


\section{ARTTIE $Y$}

Ipplied Resseirl'hes in Teednicis, Technologies and Eductation Journal of the Faculty of Technics and Technologies, Trakia University https://sites.google.com/a/trakia-uni.bg/artte/

virtualization also applies to the network, separating the traffic management function from the network hardware [15].

\subsection{SDN Architectural Foundations}

The logical structure of SDN consists of 3 levels (Figure 1) - infrastructure layer, control layer and application layer.

\subsubsection{The infrastructure layer}

The infrastructure layer is an interconnected device (routers, switches, firewalls, etc.) whose functionality is limited to performing data transmission tasks to transmit frames from one interface to another.

\subsubsection{Control layer}

The entire intelligence of the network is concentrated in programmable SDN controllers that provide its global monitoring. SDN controllers practically change the network model from a distributed to a centralized one. They support multiple drivers that manage network behavior, optimize flow management, and meet customer service requirements for scalability and flexibility.

\subsubsection{Application layer}

SDN architectures support a suite of APIs that enable the implementation of common network services, bandwidth management, traffic regulation, QoS (service quality), and optimization of processing load.

One of the main building blocks of the SDN architectural concept is the OpenFlow protocol (Figure 1) implemented at the two ends of the interface between network infrastructure devices and SDN management software and is the first standard communication interface between management and packet transport levels. in the SDN architecture [23].

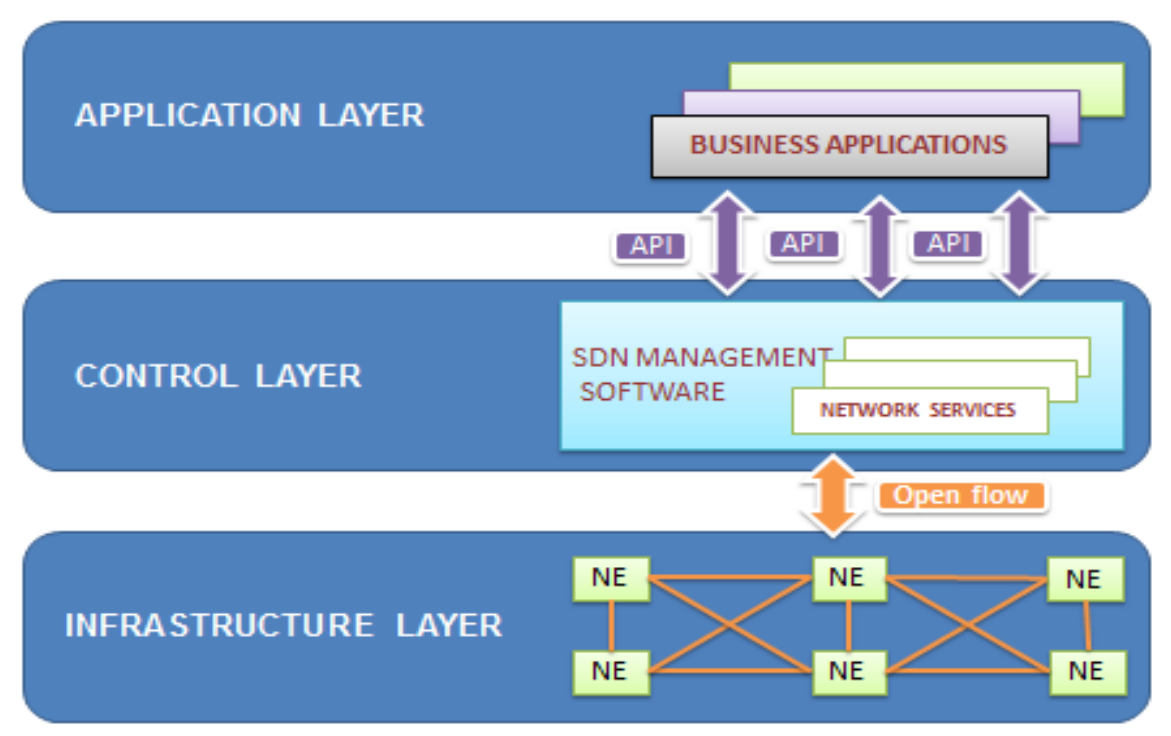

Figure 1. SDN architectural model [8]

IRTIIE Vol. 7, No. 4, 2019 ISSN 1314-8788 (print), ISSN 1314-8796 (online), doi: 10.15547/artte.2019.04.003 


\section{ARTTIE $Y$}

Ipplied Resseirlohes in Technics, Technologies and Bductation

Journal of the Faculty of Technics and Technologies, Trakia University https://sites.google.com/a/trakia-uni.bg/artte/

It is currently the most widely used standardized tool for building SDN networks. The idea for OpenFlow originated in 2006, initially aiming to develop a protocol for experimental application, but in the course of its work it was found that OpenFlow could replace the protocols used in modern switches and routers by the Channel and Network layer. the reference OSI model. A completely new protocol has been created that manages network traffic between switches and routers of different vendors through program management. In this way, configuring and managing them is outsourced to hardware specially designed controllers. The first version of OpenFlow was released in late 2009, and in March 2011, the Open Network Foundation (ONF) was created, a non-profit organization comprising representatives of leading technology giants and academia whose main mission is to promote and the distribution of SDN networks based on the OpenFlow protocol [8].

Two main models can be identified with respect to the SDN management model.

\subsubsection{Model of centralized control}

In the context of computer networks, centralized control refers to the management of a particular group of resources through one basic control unit. The architecture of softwaredefined networks represents precisely this model for controlling the control plane (Figure 2). In this type of management, all requests are sent to the controller, which processes them and returns the corresponding response to the network elements (MEs) from the access layer. This is possible due to the fact that the controller is the only element of the network that has a global view of the topology, which allows it to make the most optimal decision on how a traffic can be switched or routed through the network.

Model of decentralized management. With SDN, the control plane is logically separated from the physical plane and it is necessary to find an appropriate approach to distribute the control layer control over the network elements of the access layer. In the case of a large number of requests to the control plane, the total load can be distributed among the controllers, which eliminates the problem of congestion, a major problem in centralized management. In the event that one of the controllers fails, there will always be another controller to take over its control, while at the same time the network will remain fully operational. These are just one of the many benefits of decentralized management.

The decentralized management of software-defined networks is conditionally divided into two main sub-groups - global management (Figure 3) and local view of the network topology [15].



Figure 2. Centralized control of the SDN network [15]

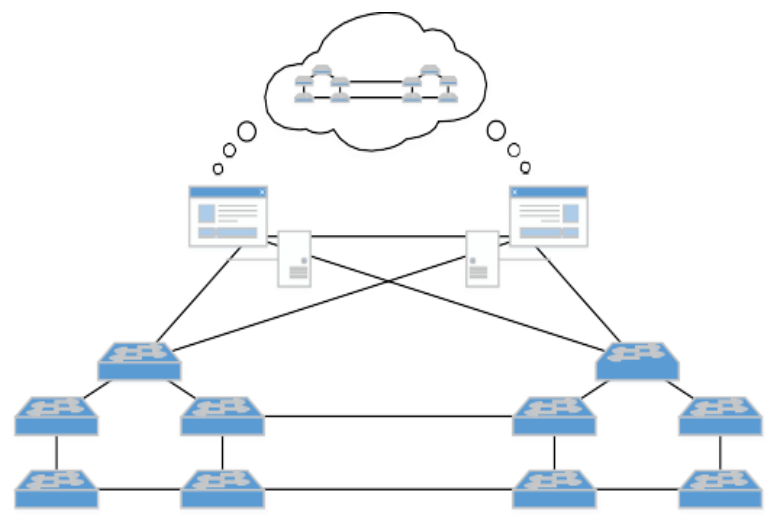

Figure 3. Architecture of a decentralized control plane with a global perspective on network topology [15] 


\subsection{A comparative analysis of traditional and SDN}

Table 1 presents a comparative analysis by major criteria of traditional and SDN networks.

Table 1. A comparison of traditional and SDN networks [20, 23, 8, 10]

\begin{tabular}{|c|c|c|}
\hline Criterion & Traditional networks & SDN \\
\hline 1 & 2 & 3 \\
\hline Topology & Hierarchical tree topology & Unconventional, new \\
\hline $\begin{array}{l}\text { Common or separate } \\
\text { conversion of network } \\
\text { management and referral } \\
\text { mechanisms packages }\end{array}$ & Common & Separated \\
\hline Network management & $\begin{array}{l}\text { Distributed, difficult, and slow to } \\
\text { implement (when changing - adding } \\
\text { or removing device / s - } \\
\text { reconfiguring separately for each } \\
\text { device) }\end{array}$ & $\begin{array}{l}\text { Centralized, easier (using } \\
\text { Controller/s) }\end{array}$ \\
\hline $\begin{array}{l}\text { Flexibility with regard to } \\
\text { device addition (Scalability) }\end{array}$ & $\begin{array}{l}\text { Static network architecture, with } \\
\text { new devices difficult to add (must } \\
\text { be configured and configured } \\
\text { manually by each individual device) }\end{array}$ & $\begin{array}{l}\text { Easily and quickly adding of new } \\
\text { devices }\end{array}$ \\
\hline $\begin{array}{l}\text { Flexibility to add new } \\
\text { services provided by the } \\
\text { network }\end{array}$ & Difficult to add new services & $\begin{array}{l}\text { Easily adapt to the requirements } \\
\text { of creating and adding new } \\
\text { services through the SDN } \\
\text { controller }\end{array}$ \\
\hline Traffic model & Client - server & $\begin{array}{l}\text { Horizontally (between server } \\
\text { machines) }\end{array}$ \\
\hline $\begin{array}{l}\text { Depending on the } \\
\text { manufacturer }\end{array}$ & $\begin{array}{l}\text { Requirements for new services and } \\
\text { network capabilities, but lack of } \\
\text { equipment needed (years to build) }\end{array}$ & $\begin{array}{l}\text { Limited manufacturer-dependent } \\
\text { software solutions }\end{array}$ \\
\hline $\begin{array}{l}\text { Convenience in } \\
\text { virtualization environment } \\
\text { (when exchanging } \\
\text { information between } \\
\text { multiple virtual machines) }\end{array}$ & $\begin{array}{l}\text { Difficult to work in a virtualization } \\
\text { environment - requires precise } \\
\text { network addressing and } \\
\text { segmentation on traditional } \\
\text { networks }\end{array}$ & $\begin{array}{l}\text { Creates application } \\
\text { environments that are distributed } \\
\text { among multiple virtual machines } \\
\text { that generate data streams with } \\
\text { each other }\end{array}$ \\
\hline Security and protection & $\begin{array}{l}\text { It is difficult and slow to reconfigure } \\
\text { access lists across the entire } \\
\text { network }\end{array}$ & Centralized \\
\hline $\begin{array}{l}\text { Distribution of network } \\
\text { resources }\end{array}$ & Static & $\begin{array}{l}\text { Better and dynamic allocation of } \\
\text { resources as needed }\end{array}$ \\
\hline Network Protocols & $\begin{array}{l}\text { They work with multiple protocols } \\
\text { that solve specific tasks }\end{array}$ & OpenFlow \\
\hline Network devices & Many complex devices & Simplified \\
\hline $\begin{array}{l}\text { Adapting to the change in } \\
\text { traffic (providing the } \\
\text { necessary bandwidth and } \\
\text { quality) }\end{array}$ & $\begin{array}{l}\text { Static, difficult to adapt to the } \\
\text { changing demands of traffic, } \\
\text { applications and users. }\end{array}$ & $\begin{array}{l}\text { They adapt easily to the } \\
\text { dynamically changing } \\
\text { requirements of traffic, } \\
\text { applications and users }\end{array}$ \\
\hline $\begin{array}{l}\text { Costs for increased network } \\
\text { requirements in terms of } \\
\text { sizes and types of services }\end{array}$ & $\begin{array}{l}\text { Costs for new specialized devices } \\
\text { and time to deploy them }\end{array}$ & $\begin{array}{l}\text { No need to use new specialized } \\
\text { devices. Reducing the cost of } \\
\text { maintaining network equipment } \\
\text { and the communications network } \\
\text { as a whole }\end{array}$ \\
\hline Global Network View & Difficult to present & Centered view from controller/s \\
\hline Maintenance costs & Higher & Lower \\
\hline
\end{tabular}

IRTITE Vol. 7, No. 4, 2019 ISSN 1314-8788 (print), ISSN 1314-8796 (online), doi: 10.15547/artte.2019.04.003 

https://sites.google.com/a/trakia-uni.bg/artte/

\begin{tabular}{|c|c|c|}
\hline 1 & 2 & 3 \\
\hline $\begin{array}{l}\text { Time needed for updating / } \\
\text { processing errors }\end{array}$ & $\begin{array}{l}\text { Sometimes it takes months for } \\
\text { individual devices }\end{array}$ & $\begin{array}{l}\text { Much easier because of the } \\
\text { centrality controller/s }\end{array}$ \\
\hline Availability of controller & $\begin{array}{l}\text { They also function without a } \\
\text { controller }\end{array}$ & $\begin{array}{l}\text { They cannot function without a } \\
\text { controller }\end{array}$ \\
\hline Using the controller & $\begin{array}{l}\text { They also function without a } \\
\text { controller }\end{array}$ & $\begin{array}{l}\text { They cannot function without a } \\
\text { controller }\end{array}$ \\
\hline $\begin{array}{l}\text { Integrity and consistency in } \\
\text { the operation of the } \\
\text { controller/s }\end{array}$ & $\begin{array}{l}\text { They also function without a } \\
\text { controller }\end{array}$ & $\begin{array}{l}\text { Critical to the operation of the } \\
\text { network }\end{array}$ \\
\hline $\begin{array}{l}\text { Integrity and consistency of } \\
\text { routing tables and network } \\
\text { status }\end{array}$ & Important & Important \\
\hline Use of resources & Incomplete & High usability \\
\hline Trained staff & $\begin{array}{l}\text { Trained staff with years of } \\
\text { experience in using conventional } \\
\text { networks }\end{array}$ & Missing so far \\
\hline Standardization & Highly standardized & $\begin{array}{l}\text { Low level of standardization, } \\
\text { which to some extent creates } \\
\text { problems in their use but is } \\
\text { developing }\end{array}$ \\
\hline $\begin{array}{l}\text { Networking experience } \\
\text { (debugging, problems, sub- } \\
\text { optimal functioning) }\end{array}$ & Years of experience and research & $\begin{array}{l}\text { They have been used relatively } \\
\text { recently, and studies are being } \\
\text { conducted to optimize their } \\
\text { performance }\end{array}$ \\
\hline
\end{tabular}

Some of the characteristics of the two types of networks presented in Table 1 will be discussed. One of the disadvantages of conventional networks is their complexity, which makes them very difficult to manage. Traditional networks include a diverse range of devices: routers, switches, traffic balancing devices, firewalls, vulnerability detection systems, etc. that work with sophisticated distributed control software that is typically closed-end and belongs to the manufacturer of the the equipment. On the other hand, this network architecture uses network protocols that go through years of development, standardization and interoperability testing.

Regarding the performance of traditional and SDN networks in a virtualization environment, it can be noted that the applications and services used today by the business are no longer deployed on a single server, but on multiple virtual machines. The main idea behind this approach is to make better use of the available server resources. However, to ensure the seamless functioning of virtual machines, IT professionals in business organizations must plan carefully to address and segment the network on traditional networks [8].

IP-based data, voice and video networks are widely used today. These networks can deliver the required level of service quality by prioritizing traffic from different applications, but in general, implementation is not automated. For traditional networks, IT professionals need to configure each device individually, adjusting parameters such as network bandwidth and quality of session and application services.

Centralization of management has many advantages - it facilitates the introduction of new services, facilitates the configuration and control of networks, increases security and many others, but is accompanied by issues affecting the scalability and reliability of networks. The questions are "will a device manage to control a single network" and "will it affect performance". Obviously, the control plane is a critical element for new generation networks. It is clear that a single controller would cause performance degradation, so strategies for implementing centralized management across multiple physical controllers are proposed in next-generation networks. Research has been done in this area [10].

IRTIIE Vol. 7, No. 4, 2019 ISSN 1314-8788 (print), ISSN 1314-8796 (online), doi: 10.15547/artte.2019.04.003 


\section{IRITIE \\ ( \\ Ipplied Resseirl ches in Technics, Technologies and Bductition \\ Journal of the Faculty of Technics and Technologies, Trakia University https://sites.google.com/a/trakia-uni.bg/artte/}

\section{APPLICATION OF SDN AND DEVELOPMENT PROSPECTS}

Figure 4 presents the growth of the global SDN market, which clearly shows the rapidly growing applicability of this modern network technology.



Figure 4. Global SDN market growth [8]

The following SDN applications are known:

\subsection{Networks of enterprises/ organizations}

Businesses often use huge systems while having strict security and compliance requirements. Depending on the unique conditions, completely different needs, qualities and customers may be present. For example, university systems can be seen as an exceptional case of large business systems: in such a domain, a large number of associated devices are volatile and unmanaged by the university, further difficult to secure and allocate assets.

SDN can be used to streamline the system by freeing it from the intermediate devices and coordinating their activity inside the system controller. Some good practices in the network environment that have been implemented using SDN include NAT, firewalls, balancing stacks $[6,14,17]$ and control organization $[12,18]$. Due to the multiplicity of intermediate devices with functions that cannot be performed directly (for example, after extensive packet testing), an SDN can be used to integrate control and administration [5, 14]. SDN helps to create a business capable of adapting to industry and market changes, with the latter allowing organizations to be truly productive and flexible [11].

\subsection{Data centers}

Server centers are developing at a staggering pace, and have recently been striving to respond to progressively increasing demands. The requirement for careful administration and the right strategy is paramount when operating on such a large scale, especially when any interruption or delay can cause gigantic profitability or a potential disruption. Due to the difficulty of designing systems of this magnitude and complexity to accommodate application needs, server centers are often provided with the highest priority of the query and therefore often work well below the limit as they are ready to quickly gain higher workloads loads. In mid-2012, Google presented a case of really using the idea and design of SDN with respect to server centers. At the Open Network Summit [21], the organization demonstrated a largescale use of an SDN-based system that interacts with server centers [7]. It presents in detail the plan, use, and evaluation of the B4 WAN linking Google server centers around the world.

IRTTEE Vol. 7, No. 4, 2019 ISSN 1314-8788 (print), ISSN 1314-8796 (online), doi: 10.15547/artte.2019.04.003 


\section{ARTTIE $Y$}

Ipplied Resseirlohes in Technics, Technologies and Bductation

Journal of the Faculty of Technics and Technologies, Trakia University https://sites.google.com/a/trakia-uni.bg/artte/

One of the first and largest SDNs is described. An achievement in this case is the design of retargeting and movement, and the way in which flexibility, adaptation to non-critical faults, necessary costs and control cannot be achieved through conventional WAN engineering methods. A modified layout has been proposed and OpenFlow-based SDN engineering has been developed to control individual switches. After three years in operation, the B4 appears to be productive as it drives many connections at almost $100 \%$ usability. In addition, the experience described in the development shows that the problem resulting from the interaction between the control plane and the data plane and the cost of writing computer programs to describe the equipment are essential issues to be considered in future work.

\subsection{Security services}

The current virtualization ecosystem supports a specific virtual service that works in the network layer. This means a feature incorporating Network functions virtualization (NFV) in SDN platforms. This type of network security creates a truly proactive environment that is able to reduce risk and respond to incidents very quickly. Today, as we see an everincreasing pervasive threat to network security, it is essential to quickly identify attacks and to ensure that other network components are protected.

\subsection{Tape management}

Using SDN applications, operators can use bandwidth management to ensure end users receive online video viewing and optimum browsing results. An SDN application can monitor traffic requirements and provide the user with streams that meet the latency and bandwidth requirements of the Layer 7 application. This type of bandwidth management application also provides better quality for users and better video playback [11].

\subsection{Wireless networks}

A specific example of the application of SDN in wireless Wi-Fi is given in [9]. Figure $5 \mathrm{a}$ presents the communication between the components in software-defined Vehicular Ad Hoc Networks (VANETs). In a typical VANET, vehicles communicate with each other via V2V communication in an ad hoc manner, and V2I communication via road units (RSU) and mobile broadband (eg 4G/ LTE).
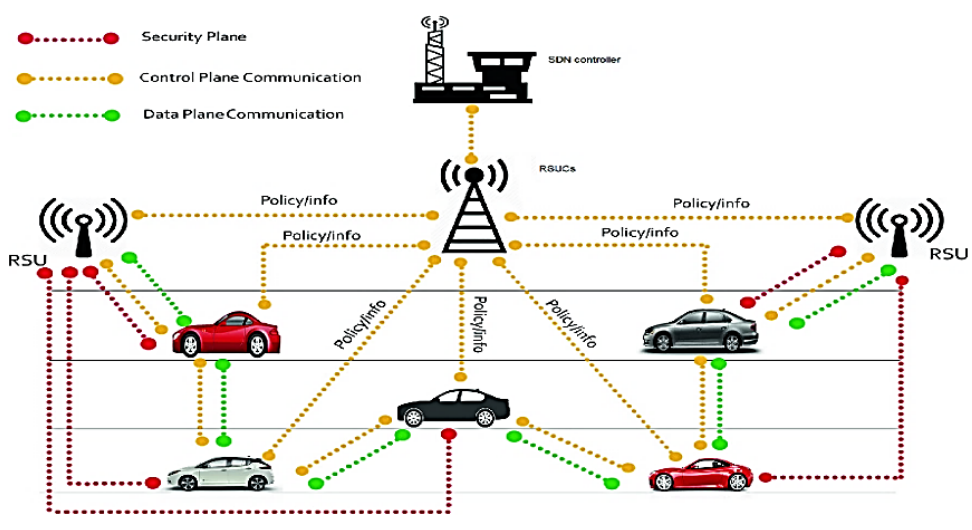

a)
Control channel Information channel

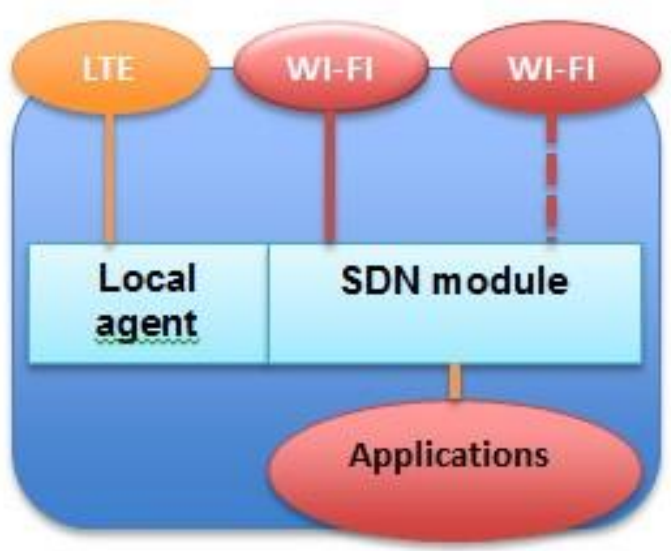

б)

Figure 5. Software-Defined VANET communications [9]

IRTIIE Vol. 7, No. 4, 2019 ISSN 1314-8788 (print), ISSN 1314-8796 (online), doi: 10.15547/artte.2019.04.003 


\section{ARTTE $Y$}

Ipplied Resseirlohes in Technics, Technologies and Bductation

Journal of the Faculty of Technics and Technologies, Trakia University https://sites.google.com/a/trakia-uni.bg/artte/

VANET's traditional services include road safety services, efficiency and traffic management services, as well as infotainment services. Efficiency and traffic management services aim to improve traffic flow, traffic coordination and provide information (map, etc.). Information and entertainment services aim to provide information and entertainment such as multimedia data transfer and global Internet access.

Figure $5 \mathrm{~b}$ shows the internal components of an SDN wireless node. It contains all the functionality of a switch in traditional OpenFlow networks, as well as additional intelligence that allows different modes of operation in VANET environments. The number of WiFi interfaces used as a data channel is determined by the configuration and service that the SDN wireless node must support. The SDN module is a combination of packet processing and an interface that receives input from a separate control plane.

One feature of Ad hoc networks is that nodes act as hosts (send/ receive traffic) and routers (redirect traffic on behalf of other nodes).

The application of SDN is not limited to the above examples. A number of publications discuss the benefits of using them in optical communications systems, implementation of home and small business systems [14], distributed application management, Cloud integration [11] and more.

\section{CONCLUSION}

Software-defined networks (SDNs) are changing the way networks are designed and managed. This is a contemporary network concept that allows network administrators to easily manage network services and resources by differentiating the management plane from the data transport plane. The control plane performs a function that makes decisions about where traffic should be sent while the data transport plane routes the traffic according to the decisions made by the control plane. In current networks, both planes are completely interconnected in the same hardware. Physically separating the management plane from the data (switching / routing) plane of the data makes the networks more flexible, cost-effective, centrally managed and fully software-enabled.

Unlike traditional networks, SDN uses a single control plane, capable of managing multiple planes for data transport. The latter simplifies the entire network layer and provides in-depth control over the entire data center system, services and applications. Not only the way packets are transmitted is completely replaced, but also the way the network is built and managed.

The SDN infrastructure creates an environment for exciting new applications that cannot be implemented on traditional networks. These applications are used by organizations for many functions and can have a positive impact on business and all users of network services.

Modern multimedia applications, cloud computing, big data, etc. require more flexible networks. SDN is considered to be the best option for meeting their high requirements.

The advantages of SDN over traditional networks are significant - improved configuration, high performance, innovation and overall adaptation to the new rapidly changing requirements of today's networks.

\section{REFERENCES}

[1] Banafa A. (2014). Software-Defined Networking (SDN), Apr 27, 2014, pp. 1-4. https://www.researchgate.net/publication/264231705_Software-

Defined_Networking_SDN_An_Opportunity. [available on 22.10.2019].

[2] Casado M., Freedman M., Pettit J., Luo J., McKeown N., Shenker S. (2007). Ethane: Taking control of the enterprise. ACM SIGCOMM Computer Communication Review, Vol. 37, No. 4, 2007, pp. 1-12.

IRTIIE Vol. 7, No. 4, 2019 ISSN 1314-8788 (print), ISSN 1314-8796 (online), doi: 10.15547/artte.2019.04.003 


\section{ARTTIE $Y$}

Ipplied Resseirlohes in Technics, Technologies and Bductation

Journal of the Faculty of Technics and Technologies, Trakia University https://sites.google.com/a/trakia-uni.bg/artte/

[3] EINashar E. A., Zlatev Z. (2016). Analysis of data from software sensor for smart airbags deployment. Proceedings of the International Conference on Technics, Technologies and Education ICTTE 2016, November 17-18 2016, Yambol, Bulgaria, pp. 280-287.

[4] Feamster N., Jennifer R., Ellen Z. (2014). The road to SDN: an intellectual history of programmable networks. ACM SIGCOMM Computer Communication Review, 44.2, 2014, pp. 87-98.

[5] Gembe A., Prabhu P., Ghadiyali Z., Akella A. (2012). Towards software-defined middlebox networking. 2012, pp. 1-6.

[6] Handigol N., Seetharaman S., Flajslik M., McKeown N., Johari R. (2009). Loadbalancing web traffic using openflow. Deutsche Telekom ACM SIGCOMM Demo, 2, pp. 1-2.

[7] Jain S., Kumar A., Mandal S., Joon O., Poutievski L., Singh A., Venkata S., Wanderer J., Zhou J., Zhu M. (2013). Experience with a globally-deployed software defined wan. Conference on SIGCOMM, ACM, 2013, pp. 3-14.

[8] Krumov, K. (2016). Software-Defined Networks as a Basis for the Information Infrastructure of the Future. Dialogue, No. 3, pp. 80-92. (in Bulgarian).

[9] Ku I., Lu Y., Gerla M., Gomes R., Ongaro F., Cerqueira E. (2015). Towards SoftwareDefined VANET: Architecture and Services. 2015, pp. 2-6.

[10] Kyuchukova D. (2017). Methods and Algorithms for Increasing Productivity of SoftwareDefined Networks. PhD thesis. "Angel Kanchev" University of Ruse, pp.8-13. (in Bulgarian).

[11] Madhava K. (2019). https://lavellenetworks.com/sdn-applications/. [available on 01.10.2019].

[12] Nayak A., Reimer A., Feamster N., Clark R. (2009). Dynamic access control for enterprise networks. Proceedings of the 1st ACM workshop on Research on enterprise networking, ACM, 2009, pp.11-18.

[13] Nunes B. (2014). A survey of software - defined networking: Past, present, and future of programmable networks. 2014, pp.1-18.

[14] Patel V., Vashi D. (2017). A Survey of Software-Defined Networking. International Journal of Engineering Technology Science and Research IJETSR, ISSN 2394-3386, Vol. 4, No. 11, pp. 669-683.

[15] Raichev J., Kinaneva D., Hristov G., Zahariev P. (2018). Comparative analysis of options for building a decentralized control plane for software-defined networks. XXVI Telecom Conference, pp. 85-92. (in Bulgarian).

[16] Sharma A., Sood M. (2015). Network Flexibility and Policy making in Software DefinedNetworks.https://journals.scholarpublishing.org/index.php/TNC/article/view/1517/ 871. [available on 26.11.2019].

[17] Wang R., Butnariu D., Rexford J. (2011). Openflow-based server load balancing gone wild. Workshop of HotICE, Vol. 11, 2011, pp. 1-6.

[18] Zlatarov P., Ivanova G. (2016). Web based monitoring and notification application for network server problems. Proceedings of the SNA of the University of Rousse "Angel Kanchev", Ruse, 2016, ISBN 1311-3321, pp. 133-137. (in Bulgarian).

[19] Zlatev, Z., Dimitrova, A., Baycheva, S., Vasilev, M. (2016). Analysis of information processes in the production of yogurt. Journal of Innovation and entrepreneurship, Vol. 4, No. 2, 2016, ISSN 1314-9180, pp. 43-59.

[20] Singh A. K., Srivastava Sh. (2018). A survey and classification of controller placement problem in SDN. Network Management, Vol. 28, Issue 3. https://www.researchgate.net/publication/323974224_A_survey_and_classification_of_c ontroller_placement_problem_in_SDN. [available on 22.10.2019]. 


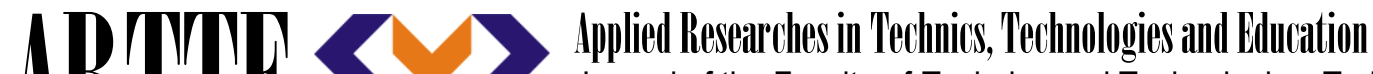 Journal of the Faculty of Technics and Technologies, Trakia University https://sites.google.com/a/trakia-uni.bg/artte/}

[21] Inter-Datacenter WAN with centralized TE using SDN and OpenFlow. https://www.opennetworking.org/wp-content/uploads/2013/02/cs-googlesdn.pdf. [available on 02.11.2019].

[22] Leading Service Providers Unveil Their Strategic Plan for the ONF to Drive Open Source Solutions Into Production. www.opennetworking.org. [available on 12.09.2019].

[23] SDN - Divide and conquer. https://cio.bg/management/2014/06/20/3440655_sdn__razdeliai_i_vladei/. [available on 20.06.2019]. (in Bulgarian).

IRTIIE Vol. 7, No. 4, 2019 ISSN 1314-8788 (print), ISSN 1314-8796 (online), doi: 10.15547/artte.2019.04.003 